STANISLAW GUCMA, PAWEL ZALEWSKI

Maritime University of Szczecin

\title{
DETERMINISTIC-PROBABILISTIC METHOD OF WATERWAY DESIGN PARAMETERS DETERMINATION
}

\begin{abstract}
The paper presents a method of recommended waterway parameters determination, based on modified relationships derived from actual empirical research - the authors' combination of PIANC and Canadian deterministic methods and stochastic relationships). These relationships are mostly discontinuous functions (e.g. of ship type variable, speed, method of determining the position, etc.), which can be approximated by continuous spline functions. Application built in $\mathrm{C} \#$ allows determining the recommended minimum width of the waterway, the width increase due to the accuracy of the vessel positioning method, and the minimum radius of waterway bends. The results can be further utilized in the Decision Support System for Water Transport Safety.
\end{abstract}

\section{Keywords:}

waterway design parameters, safety analysis, safety management.

\section{INTRODUCTION}

Considering requirements for under keel clearance and dimensions of safe manoeuvring water area the basic condition of navigation safety can be written as [3, 4]:

$$
\overbrace{\substack{h(x, y, t) \geq T(x, y, t)+\Delta(x, y, t) \\ \mathrm{p}(\mathrm{x}, \mathrm{y}) \in \mathbf{D}(\mathrm{t})}}^{\mathbf{d}_{\mathrm{ijk}} \subset \mathbf{D}(\mathrm{t})}\}
$$

where:

$h(x, y, t) \quad$ - depth at area point of $(x, y)$ coordinates in moment $t$;

$T(x, y, t)$ - draught of ship at area point of $(x, y)$ in moment $t$;

$\Delta(x, y, t)$ - reserve of under keel clearance at area point of $(x, y)$ in moment $t$. 
Sets of accessible sailing area $\mathbf{D}(t)$, and safe manoeuvring area $\mathbf{d}_{\mathrm{ijk}}$ can be identified with areas of specific linear parameters. The basic parameters deciding of safety of analysed manoeuvre in a fairway are fairway's widths. Due to this the condition of safe performance of the specified manoeuvre can be transformed to:

$$
D(t)_{i j k} \geq d_{i j k}
$$

where:

$D(t)_{i j k}$ - width of a waterway at bottom in moment $t$ (accessible sailing area of an $i$-th vessel carrying out $j$-th manoeuvre in $k$-th navigation condition);

$d_{i j k} \quad$ - safe width of a waterway for $i$-th ship, carrying out $j$-th manoeuvre in $k$-th navigation conditions.

The safe width of a waterway can be determined by utilizing one of the two models of ship's motion in restricted water areas:

- deterministic model;

- probabilistic model.

In the deterministic model the safe width of a waterway is defined as function of ship's parameters $(i)$, performed manoeuvre $(j)$ and present navigation conditions $(k)$ :

$$
d_{i j k}=f(i, j, k)
$$

In the probabilistic model the safe width of a waterway is defined as a random variable. To describe this parameter the normal (Gauss) distribution is usually preferred as it shows high fidelity to reality. The probability density function of distance of extreme points of the manoeuvring area to the fairway axis (centre) can be expressed as [3][4]:

$$
\begin{aligned}
& f\left(d_{l}(y)\right)=\frac{1}{\delta_{l} \sqrt{2 \Pi}} e^{-\frac{\left(y-m_{l}\right)^{2}}{2 \delta_{l}^{2}}} \\
& f\left(d_{p}(y)\right)=\frac{1}{\delta_{p} \sqrt{2 \Pi}} e^{-\frac{\left(y-m_{p}\right)^{2}}{2 \delta_{p}^{2}}}
\end{aligned}
$$

where:

$d_{l}(y) ; d_{p}(y)$ - distances from the centre of the waterway to port and starboard limit of the manoeuvring area;

$m_{l} ; \delta_{l} \quad$ - average and standard deviation of the distances from the centre of the water way to port limit of the manoeuvring area; 
$m_{p} ; \delta_{p}$ - average and standard deviation of the distances from the centre of the waterway to starboard limit of the manoeuvring area.

And the safe width (assuming negative values to port from the centre of the waterway):

$$
d_{\alpha}=-d_{l \alpha}+d_{p \alpha}=-m_{l}-k_{\alpha} \delta_{l}+m_{p}+k_{\alpha} \delta_{p}
$$

where:

$d_{\alpha}$ - safe width of a waterway at the specified confidence level $1-\alpha$;

$k_{\alpha}$ - coefficient dependent on the confidence level or probability: $k \approx 2$ for $p=1-\alpha=0.95$.

The methods to define a safe width of a waterway can be divided into analytical (theoretical and empirical) and simulation ones depending on the approach used for obtaining the solution.

In the analytical model the safe width of the manoeuvring area at straight segment of the waterway can be defined by $[3,4]$ :

where:

$$
d=2\left(d_{n}+d_{m}\right)+d_{r}
$$

and:

$$
d_{m}=d_{m 1}+d_{m 2}
$$

$d_{n}$ - navigation component of the width of a manoeuvring area (lane of ship's motion) [m];

$d_{m}$ - manoeuvring component of the width of a manoeuvring area (lane of ship's motion) [m];

$d_{r}$ - additional component of the width of a manoeuvring area (reserve for bank clearance) [m];

$d_{m 1}$ - the width of the lane covered by ship's centre of gravity while yawing;

$d_{m 2}$ - the width of the lane covered by ship's hull extending outside the motion trajectory.

Theoretical methods include the three components method [3] which describes elements of ship's motion by deterministic models and elements of ship's position by probabilistic model.

The fundamental empirical methods based on deterministic models are:

- the Panama Channel method [6];

- PIANC [5];

- Canadian [2];

- USACE or ASCE [1].

Empirical methods built on deterministic models evaluate fixed value of safe waterway width for the preliminary set navigation conditions, assuming that the evaluated width ensures safety of manoeuvring in the set conditions. This width is determined by non-simulation research, usually expert or statistical, each interpreting differently the safety definition according to predefined assumptions. 
The construction of Gucma method (called INM method) presented in [3] is different. It is empirical method in which the manoeuvring component of waterway width is evaluated by a deterministic model but the navigation component is determined by a probabilistic model (similarly to strictly theoretical three components method). This method utilizes the Panama Channel method for calculation of the manoeuvring component of waterway width [6].

Simulation methods are the most important studies leading to determination of safe manoeuvring area parameters.

The fundamental criteria of simulation methods classification used in marine traffic engineering systems are time and means of ship control. Considering time of simulation these methods can be divided into:

- RTS - Real Time Simulation;

- FTS - Fast Time Simulation.

Considering means of ship control the simulation methods can be divided into:

- simulation with non-autonomous models;

- simulation with autonomous models.

In simulation non-autonomous models the ship is controlled by human operator (the navigator) while in simulation autonomous models the ship is controlled by a mathematical model of real navigator.

A method generalizing simulation research results can be also utilized for assessing the width of safe manoeuvring area. This method allows evaluating parameters of safe manoeuvring area by post processing of simulation experiments for various ships, manoeuvres and navigation conditions. The final safe width of manoeuvring area is determined at specified confidence level by the regression analysis.

Simulation methods present best credibility for assessment of safe manoeuvring water areas especially for complicated manoeuvres in restricted waters and difficult navigational conditions. The empirical methods algorithmized by the authors and presented in this article can be applied for less complicated manoeuvres like passing straight legs and bends of a harbour approach fairway.

\section{DETERMINISTIC-PROBABILISTIC METHOD OF WATERWAY SAFE WIDTH DETERMINATION}

The research conducted in Institute and Centre of Marine Traffic Engineering in Maritime University of Szczecin proved that on straight waterways the PIANC method results are closest to simulation ones. Utilizing this method the new deterministic-probabilistic method named MTEC method has been developed. 
In this method the manoeuvring component of the ship's lane $\left(d_{m}\right)$ is evaluated deterministically and navigation component is of probabilistic nature and it is evaluated at specified confidence level as $d_{n}(1-\alpha)$.

Taking into consideration that both navigation components (port and starboard) at straight waterways segments are equal:

$$
d_{n}^{p}(1-\alpha)=d_{n}^{l}(1-\alpha)=d_{n}(1-\alpha)
$$

and additional widths for bank clearance to port and starboard are also equal:

$$
d_{r}^{p}=d_{r}^{l}=d_{r}
$$

the resultant width of manoeuvring area (ship's lane) at specified confidence level $(1-\alpha)$ will be:

$$
D \geq d(1-\alpha)=d_{m}+2 d_{n}(1-\alpha)+2 d_{r}
$$

where:

$d(1-\alpha) \quad$ - the width of the manoeuvring area (ship's path) at confidence level of $(1-\alpha)[\mathrm{m}]$;

D - the recommended width of the manoeuvring area;

$d_{m} \quad$ - the manoeuvring component of the manoeuvring area;

$d_{n}^{p}(1-\alpha) ; d_{n}^{l}(1-\alpha)$ - the navigation components of the manoeuvring area at confidence level $(1-\alpha)$,

$d_{r}^{p} ; d_{r}^{l} \quad$ - additional widths for bank clearance to starboard and port.

The algorithm for determination of manoeuvring component of a waterway width has been based on PIANC method [5] modified by CMA method [2] for bends and expert method for manoeuvring with tugs.

For a vessel manoeuvring without tugs the relations for the following parameters have been adopted directly from PIANC:

- basic manoeuvring lane width $d_{m p}$;

- additional widths for bank clearance: $d_{r}^{p} ; d_{r}^{l}$;

— additional widths: $d_{2} ; d_{3} ; d_{4} ; d_{5} ; d_{8}$. 

from CMA:

And the relations for the following parameters have been adopted directly

- additional manoeuvring width at bend $\Delta D$;

- transitional zone length $l_{T}$;

- radius of waterway bend $R$.

For a ship sailing up to 12 knots the manoeuvring component takes form:

$$
d_{m}=\left\{\begin{array}{cl}
d_{m p}+d_{2}+d_{3}+d_{4}+d_{5}+d_{8}+d_{r r}+d_{r g}, & \text { if } i_{d t} \in\{1,3,5\} \\
d_{m p}+d_{2}+d_{3}+d_{4}+d_{5}+d_{8}+d_{r r}+d_{r g}+\Delta D, & \text { if } i_{d t} \in\{2,4,6\}
\end{array}\right.
$$

where:

$d_{m p} \quad$ - basic manoeuvring lane width [m];

$d_{2} \quad$ - additional width for prevailing cross wind [m];

$d_{3} \quad$ - additional width for prevailing cross current [m];

$d_{4} \quad$ - additional width for prevailing longitudinal current [m];

$d_{5} \quad$ - additional width for significant wave height [m];

$d_{8} \quad$ - additional width for depth of waterway [m];

$d_{r r}, d_{r g}$ - additional widths for bank clearance to port and starboard side [m];

$\Delta D \quad$ - additional manoeuvring width at bend $[\mathrm{m}]$;

$i_{d t} \quad$ - index of waterway type (odd numbers for straight sections, even numbers for bends).

For a vessel manoeuvring with tugs the formula for basic manoeuvring lane width is modified as follows:

$$
\begin{aligned}
& d_{m p}=k \cdot B, \text { where } k=\left\{\begin{array}{l}
1.3, \text { if good and moderate manoeuvrability } \\
1.5, \text { if poor manoeuvrability }
\end{array}\right. \\
& \text { and } d_{8}=0 .
\end{aligned}
$$

The algorithm for determination of navigational component of a waterway width has been based on RMS (root mean square) relations presented by Gucma in [4]. At straight section of a waterway the navigational component is equal to a directional error of shipboard farthest position at specified confidence level. This error is perpendicular to a fairway axis and given by the formula (3):

$$
d_{n}(1-\alpha)=p_{y B}(1-\alpha)= \pm \sqrt{p_{y}(1-\alpha)^{2}+\left(\frac{m_{K R}(1-\alpha) \cdot L_{D}}{57.3^{\circ}}\right)^{2}}
$$


where:

$d_{n}(1-\alpha)-$ directional error of shipboard position at confidence level of $(1-\alpha)[\mathrm{m}]$;

$p_{y}(1-\alpha)$ - directional error of ship's position (observer's position) at confidence level of $(1-\alpha)[\mathrm{m}]$;

$m_{K R}(1-\alpha)$ - ship's heading estimation error at confidence level $(1-\alpha)\left[^{\circ}\right]$ dependable on $i_{d t}$;

$L_{D} \quad$ - distance from ship's bridge to bow [m], for most ships approximated to $0.75 \times L O A$.

Directional errors in the formula (14) have been defined:

- for eight main positioning methods in restricted water areas: PNS (Pilot Navigation System based on DGPS), leading lights, midchannel marks as leading marks, midchannel marks as distance marks, lateral marks as leading marks, lateral or mixed marks as distance marks, mixed marks (sight leading marks), bridge leading marks (pair of buoys or beacons);

- two sub-methods: buoys or beacons (except where PNS or leading lights are used);

- four types of visibility ( $>2 \mathrm{Nm}$ at day, at night, at night with no navigation or cultural lights, restricted visibility $<2 \mathrm{Nm}$ ).

All directional errors of methods using navigation marks or bank lines/ structures have been further divided into terrestrical (optical) and radar.

The used formulas are mostly discontinuous functions (eg. of ship type variable, waterway type variable, speed, method of determining the position, etc.). The example can be navigational component of ship's path width determined for method of distance measurement to midchannel beacons [4]:

$$
d_{n}(0.95)=\sqrt{p_{y}(0.95)^{2}+\left(\frac{1.5 L O A}{57.3}\right)^{2}}
$$

where:

$$
p_{y}(0.95)=\left\{\begin{array}{l}
5, \text { if } x=100 \mathrm{~m} \\
6, \text { if } x=200 \mathrm{~m} \\
10, \text { if } x=500 \mathrm{~m} \quad \text { [m] } \\
20, \text { if } x=1000 \mathrm{~m} \\
30, \text { if } x=1 \mathrm{Nm}
\end{array}\right.
$$

$x$ - distance to the beacon. 
Such discontinuous functions as (16) have been approximated by continuous spline functions in the algorithm. In general, the $i^{\text {th }}$ spline function for a cubic spline can be written as:

$$
s_{i}(x)=a_{i}+b_{i}\left(x-x_{i}\right)+c_{i}\left(x-x_{i}\right)^{2}+d_{i}\left(x-x_{i}\right)^{3}
$$

For $n$ data points, there are $n-1$ intervals and thus $4(n-1)$ unknowns to evaluate to solve all the spline function coefficients $a_{i}, b_{i}, c_{i}, d_{i}$. One condition requires that the spline function goes through the first and last point of the interval, yielding $2(n-1)$ equations of the form:

$s_{i}\left(x_{i}\right)=f_{i} \Rightarrow a_{i}=f_{i}$

$s_{i}\left(x_{i+1}\right)=f_{i} \Rightarrow s_{i}\left(x_{i+1}\right)=a_{i}+b_{i}\left(x_{i+1}-x_{i}\right)+c_{i}\left(x_{i+1}-x_{i}\right)^{2}+d_{i}\left(x_{i+1}-x_{i}\right)^{3}=f_{i}$

Another condition requires that the first derivative is continuous at each interior point, yielding $n-2$ equations of the form:

$$
s_{i}^{\prime}\left(x_{i+1}\right)=s_{i+1}^{\prime}\left(x_{i+1}\right) \Rightarrow b_{i}+2 c_{i}\left(x_{i+1}-x_{i}\right)+3 d_{i}\left(x_{i+1}-x_{i}\right)^{2}=b_{i+1}
$$

A third condition requires that the second derivative is continuous at each interior point, yielding $n-2$ equations of the form:

$$
s_{i}^{\prime \prime}\left(x_{i+1}\right)=s_{i+1}^{\prime \prime}\left(x_{i+1}\right) \Rightarrow 2 c_{i}+6 d_{i}\left(x_{i+1}-x_{i}\right)=2 c_{i+1}
$$

These give $4 n-6$ total equations. Two additional equations are derived assuming clamped end conditions - the first derivatives at the first and last knots are known or in other words the slope of the function at the first and last knots is set according to expertly presumed extrapolation.

\section{ALGORITHM}

The general algorithm for analytical method of waterway design parameters determination is presented at block diagram in the fig. 1 . 


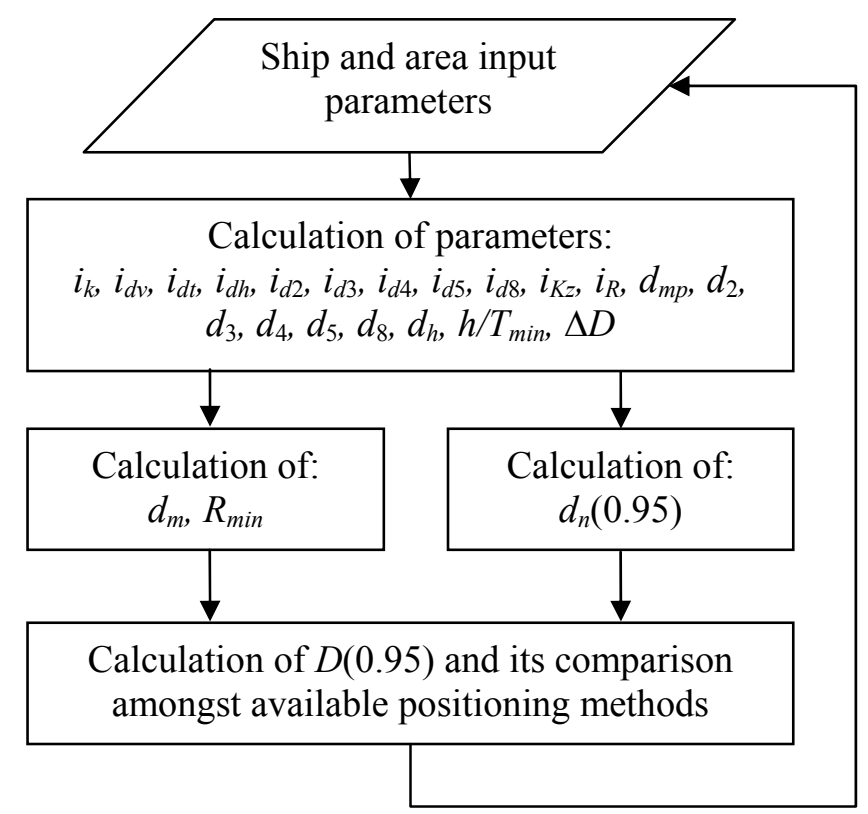

Fig 1. Block diagram of analytical method of waterway design parameters determination [own study]

Calculation of waterway width's manoeuvring component $\left(d_{m}, R_{m}\right)$ and navigation component $\left(d_{n}\right)$ is done independently of each other, but based on the common deterministic parameters defined in arrays accessible by indexes as follows:

$i_{k} \quad$ - index of parameters' array depending on ship's type;

$i_{d v} \quad$ - index of parameters' array depending on ship's speed;

$i_{d t} \quad$ - index of parameters' array depending on waterway's type

$i_{d h} \quad$ - index of parameters' array depending on tugs availability;

$i_{d 2} \quad$ - index of parameters' array depending on prevailing cross wind;

$i_{d 3} \quad$ - index of parameters' array depending on prevailing cross current;

$i_{d 4} \quad$ - index of parameters' array depending on prevailing longitudinal current;

$i_{d 5}$ - index of parameters' array depending on significant wave height;

$i_{d 8} \quad$ - index of parameters' array depending on depth of a waterway;

$i_{d K} \quad$ - index of parameters' array depending on course change at bend;

$i_{R / L}$ - index of parameters' array depending on bend radius to ship's LOA ratio. 
The discontinuity of the indexed parameters is solved by usage of spline functions as presented in chapter 2 (one example of cubic spline approximation of discontinuous function of bend radius is shown in the fig. 2).

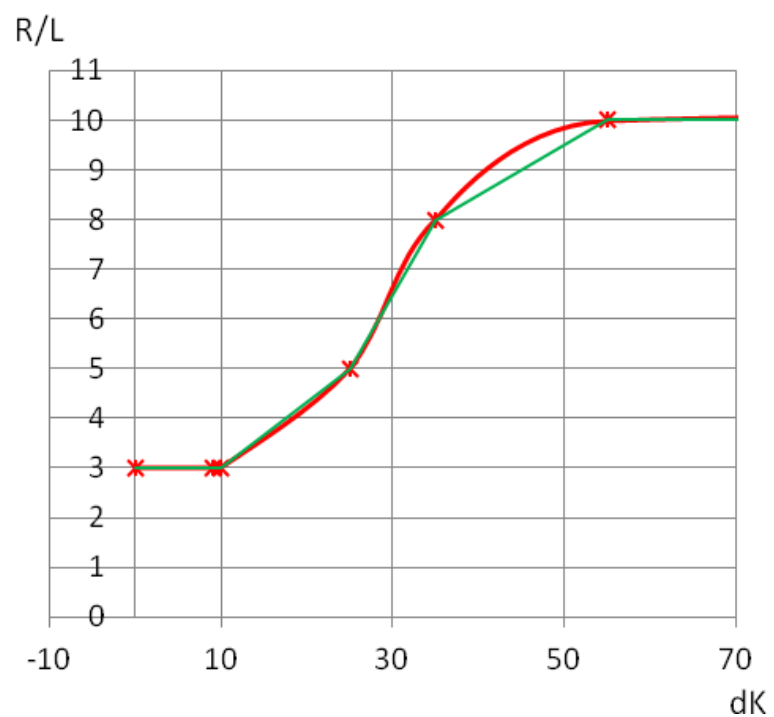

Fig. 2. Line and cubic spline approximation of discontinuous function of bend radius [own study]

In the algorithm the following steps must be performed consecutively:

1. Uploading up-to-date database of waterway parameters.

2. Choice of area type, ship type, hydrometeorological conditions, tugs assistance (defined by several parameters).

3. Calculation of deterministic waterway parameters - manoeuvring width component, bend radius.

4. Calculation of navigation width component depending on waterway type, aids to navigation, visibility.

5. Eventual risk analysis based on confidence level set in p. 4) - calculation of grounding probability and its consequences.

The test interface of the algorithm implemented in Visual C\# programming environment is presented in the fig. 3 . 


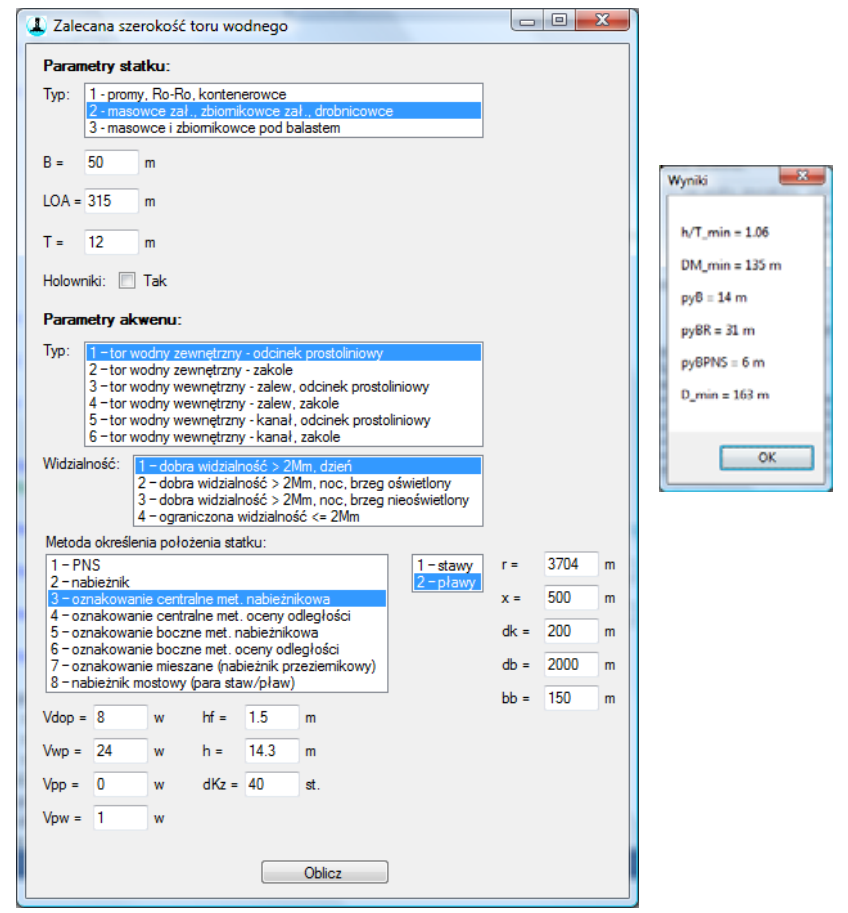

Fig. 3. Test interface for input parameters and outputs [own study]

The preliminary graphical interface is optimized according to criterion of inputs data number - therefore more user/operator friendly (fig. 4).

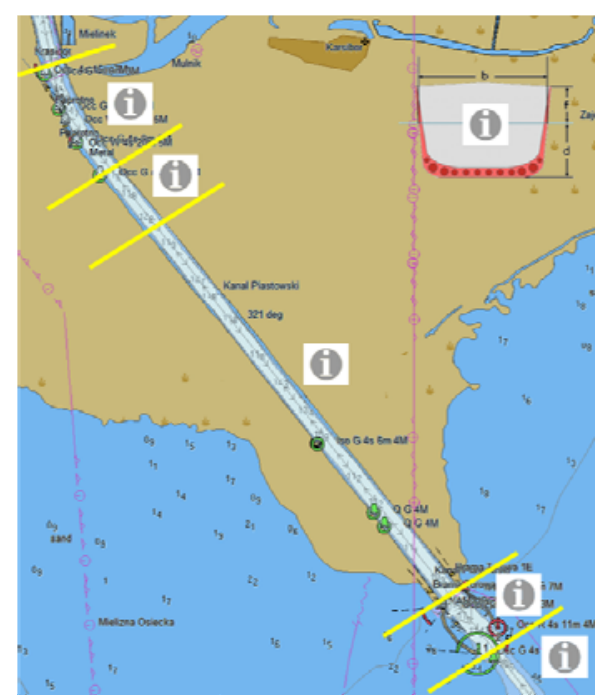

Fig. 4. Preliminary graphical operator's interface [own study] 
It enables:

- choice from predefined parameters;

- graphical choice from predefined waterway's segments and their parameters readout.

\section{CONCLUSIONS}

In the developed algorithm for analytical method of waterway design parameters determination the two components have been formulated:

- the manoeuvring component of a waterway width by deterministic formulas;

- the navigational component of a waterway width, probabilistically at the specified confidence level.

This algorithm has been implemented in the C\# allowing operator determining the recommended total minimum width of the waterway, width increase due to the accuracy of the vessel positioning method - so the total width at specified confidence level, and the radius of waterway bends. The discontinuity of the empirical and approximate functions used has been solved by means of cubic spline functions.

Developed tool can be further utilized as an element of the Decision Support System for Water Transport Safety.

\section{REFERENCES}

[1] American Society of Civil Engineers, Ship Channel Design and Operation, ASCE Manuals and Reports on Engineering 2005.

[2] Canadian Maritime Administration, Canadian Waterways National Manoeuvring Guidelines: Channel Design Parameters, Produced by Waterways Development, Marine Navigation Services, Canadian Coast Guard, Fisheries and Oceans Canada, 1999.

[3] Gucma S., Sea Traffic Engineering. Shipbuilding and Shipping, Gdańsk 2001.

[4] Gucma S., The Pilotage Navigation, The foundation of the promotion of the shipbuilding industry and the sea-economy, Gdańsk 2004.

[5] PIANC, Approach Channels. A Guide for Designs, PTC II-30, Final report of the joint Working Group PIANC and IAPH in cooperation with IMPA and IALA, Supplement to Bulletin, 1997, No. 95.

[6] Tsinker G. P. (ed.), Port Engineering: Planning, Construction, Maintenance, and Security, Headland J., Alfageme S., 10 Navigation Channel Design, John Wiley \& Sons, Inc., New Jersey, U.S.A., 2004.

Received May 2012

Reviewed September 2012 